\title{
Hospital Information Systems: The status and approaches in selected countries of the Middle East
}

Hamid Moghaddasi ${ }^{1}$, Ali Mohammadpour ${ }^{2}$, Hamid Bouraghi², Amirabbas Azizi ${ }^{3}$, Hamzeh Mazaherilaghab ${ }^{4}$

${ }^{1} \mathrm{Ph} . \mathrm{D}$. in Health Information Management and Medical Informatics, Associate Professor, Department of Health Information Technology and Management, Faculty of Paramedical Sciences, Shahid Beheshti University of Medical Sciences, Tehran, Iran

${ }^{2}$ Ph.D. in Health Information Management, Assistant Professor, Department of Health Information Technology, School of Paramedical Sciences, Hamadan University of Medical Sciences, Hamadan, Iran

${ }^{3}$ Ph.D. in Medical Informatics, Assistant Professor, Department of Health Information Technology, School of Paramedical Sciences, Ahvaz Jundishapur University of Medical Sciences, Ahvaz, Iran

${ }^{4} \mathrm{Ph} . \mathrm{D}$. in English Language, Assistant Professor, Department of English Language, School of Medicine, Hamadan University of Medical Sciences, Hamadan, Iran

\section{Type of article: Original}

\begin{abstract}
Background and aim: Since hospital information systems (HISs) are among the most important information systems in the health sector, the present study aimed to shed light upon the situation of HISs in selected countries of the Persian Gulf region to reflect national strategies and activities in the case of HISs.

Methods: In this descriptive cross-sectional study, the information about HISs status of the selected countries of the Persian Gulf region were obtained through approaches including review of national and international resources. Then, according to aspects included in HIS status, content analysis was performed. Information obtained from content analysis after several stages of reading, was categorized and then findings, presented.

Results: The findings revealed that the surveyed countries have widely used HISs since the 1980s. HIS use and development vary to a certain extent. Since the middle of the first decade of the 21 st century, Ministry of Health officials of the studied countries have considered the importance of HIS's integration and creating Electronic Health Record where, Oman, Bahrain and UAE are among the leading countries.

Conclusion: Since the emergence of HISs in healthcare centers, these countries have employed various approaches. In any case, in order to avoid wasting important resources, including financial and human ones, the use of successful experiences of other countries along with the formulation of a comprehensive plan is highly recommended while considering all HIS aspects, including national and international standards.

Keywords: Information systems, Hospital information systems, Middle East
\end{abstract}

\section{Introduction}

The Hospital Information System (HIS) is an integrated information system that provides hospital information requirements for daily operations such as planning and patient care (1). In other words, HIS is a system that can support all hospital activities including clinical, administrative and financial activities $(2,3)$. Initial HISs paid more attention to financial and administrative issues of hospitals. However, in the 1980s, because of changes in the health care system, including change in reimbursement systems of hospitals, the patient's clinical issues were considered in the design of HISs. Therefore, designers of the systems started moving toward Electronic Patient Record (EPR) (4, 5). However, due to the information-oriented nature of hospitals, technologies such as HISs are inevitable for them (6). It is very difficult to imagine how health care services are provided to outpatients and inpatients without

\section{Corresponding author:}

Assistant Professor Dr. Ali Mohammadpour, Department of Health Information Technology, School of Paramedical Sciences, Hamadan University of Medical Science, Hamadan, Iran. Tel: +98.8138381039 Fax: +98.8138381017, Email: mohammadpur2000@gmail.com and al.mohammadpour@umsha.ac.ir

Received: March 15, 2017, Accepted: February 15, 2018, Published: May 2018

iThenticate screening: February 17, 2018, English editing: March 02, 2018, Quality control: April 15, 2018

This article has been reviewed / commented by four experts

(C) 2018 The Authors. This is an open access article under the terms of the Creative Commons Attribution-NonCommercialNoDerivs License, which permits use and distribution in any medium, provided the original work is properly cited, the use is non-commercial and no modifications or adaptations are made. 
computerized information systems. Even a temporary inactivity of information network in a hospital can cause bustle and disarray that will result in a significant impact in hospital management. Furthermore, HIS plays an undeniable role in the hospital budget. Typically, around $2-5 \%$ of hospital operational budget is dedicated to HIS (7, 8). Studies also show that hospital staff spend most of their time exchanging information and notifying administrative follow-ups, but only 42 percent of their time is spent on clinical activities (9). Since HIS affects all hospital sections and departments, the satisfactory results arising from the implementation of HIS can occur in the case of comprehensive planning and efficient designing (7). Therefore, developed countries have paid serious attention to HISs. For example, in 2004, Health Information Technology (HIT) was placed at the heart of the Federal Government Program in America; consequently, the Office of National Coordinator for Health Information Technology (ONC) was formed at the Ministry of Health to coordinate the use and implementation of information technology in hospitals and physicians' offices $(10,11)$. In developing countries of the Persian Gulf region, the rapid growth of ICT (Information and Communication Technology), especially in health and hospital information systems, has resulted in transformation in the healthcare delivery system (12). But the plans related to HISs in some countries of this region, especially in Iran are believed to encounter significant problems due to the organizational complexity, including uncoordinated organizational structures with separate and non-integrated HISs (13, 14). However, as we know, hospital information systems (HISs) are among the most important information systems in the health care sector; on the other hand, there is not sufficient information about the status of HISs in the Persian Gulf region. Therefore, to reflect the strategies and activities done in this case, this study intended to shed light upon the status and approaches of HISs in some countries of the Persian Gulf region.

\section{Material and Methods}

In this descriptive cross-sectional study, the status of hospital information systems (HISs) of the selected countries in the Middle East (Iran and Arab countries around the Persian Gulf region) was surveyed. Among these countries, Bahrain, Oman, UAE (United Arab Emirates), Saudi Arabia, Iran, Kuwait and Qatar were selected, while States of Kuwait and Qatar were removed from research population due to low information or even lack of access to HISs. Finally, HIS of the States of Bahrain, Oman, UAE, Saudi Arabia and Iran formed the research population. The first HIS usage, how to use HIS (the use of internal and external products, a variety of products or a single product), the evolution and integrity of HISs and Electronic Health Record (EHR) creation are regarded as the important aspects of HISs status in the selected countries. Information about HISs of the countries was obtained through approaches including national and international resources, and through contacting the officials responsible for HISs in these countries. We searched the websites of the Ministry of Health of each country as well as global websites, including the website of the United Nations (UN), World Health Organization (WHO) and also databases such as ISI, PubMed, Google scholar, and Web search engine of Google. We also sent request-for-information e-mails to HISs officials the surveyed countries but unfortunately, we did not receive any responses, so we relied on other resources mentioned above. According to aspects included in HIS status, a check list was developed and then content analysis was performed. Information obtained from content analysis after several stages of reading, was categorized and then findings presented. The report of the study was prepared based on the journal format and other guidelines provided in this reference (15).

\section{Results}

In this section, there is an attempt to have a glimpse into the situation of hospital information systems, in the case of each country.

\subsection{Bahrain}

The process of mechanization for hospitals in Bahrain was started in the 1980s, when various approaches about HIS were adopted. The results of these approaches led to the formation of a committee in 1989 to implement the Health Information System Project, and the hospital information system as the core of this project. The committee selected the software package HOMER from the McDonnell Information System (MDIS) Company. After a contract in 1990, the first phase of the system, which included a module of PAS (Patient Administration System), was installed in the country's hospitals in 1992. Launched in 1993, the second phase contained other modules including radiology, pathology, pharmacy, physician orders and communications, and continued its activities up to 2000. In this year, the Ministry of Health (MOH) defined the MHIS (MOH Information Systems) project as the outcome of changes in the health care environment and lack of HISs communications. This project had 5 main programs including significant numbers of modules in each. The health information center located in the MOH, with the help of a foreign company (Arthur Anderson), was in charge of implementing this project. During this project, the total health information system required reengineering so that such project could cover all health, clinical, administrative, and educational 
and research activities in $\mathrm{MOH}$ hospitals and health centers. The tasks of HIS in the project is included in the core program, which covers some items such as: patient management, the patient's electronic records, ICD (International and statistical classification of diseases and related health problems), the patient appointment system, physicians' orders entry, communications, reporting systems, primary care, acute care, emergency, and accidents. The time span for the implementation of the project was 2000-2010; the project was done through outsourcing which follows the BOOT process (Build, Own, Operate and Transfer). Taking Bahrain's MOH website into account, this project was finalized by the end of 2010 (16-18).

\subsection{Oman}

To support health care activities, the first use of IT (Information Technology) in the state of Oman, refers to Royal Hospital in 1986. Along with the importance of IT in healthcare centers, the IT department was formed in the MOH in 1990. After the formation of the IT unit, a team consisting of clinicians, executive officers and IT personnel was formed to decide about the use of IT in healthcare centers. Software development by the IT specialists of the Ministry of Health aiming to support the healthcare services, was one of the most crucial decisions of the team. Therefore, in 1997, at Wadi Al Jawahir Health Center, the first in-house developed software was implemented. Also, in 1998, the first in-house developed HIS (Al- Shifa system) was implemented in Nizwa hospital. Since 1998, the process of mechanization of new centers was considered as one of the paramount strategies of the $\mathrm{MOH}$. Therefore, by 1998, all healthcare centers, including hospitals in the country onwards, were all mechanized. The centers established before 1998 were scheduled for HIS mechanization as well. Due to the emphasis of the World Health Organization on health information systems planning, the strategy of the country has been changed to e-health since 2004. In this strategy (e-health), Al- Shifa hospital information system was on the basis of all the programs of the Ministry of Health. Hence, this system was implemented in all hospitals and health centers, except Sultan Qaboos hospital. In the second phase, all current HIS systems were to become inter-connected by the end of 2007 with a middleware called e-referral engine. In phase III (final), the national repository of electronic health records was created by the end of $2010(19,20)$.

\subsection{United Arab Emirates (UAE)}

IT usage in the healthcare centers of the Emirates dates back to the 1990s. Also, the IT center at the MOH was established to facilitate the creation of mechanized information systems in healthcare centers, in 1993. Up to year 2008, both single and different HISs were implemented in the country's hospitals. In 2008, with respect to the importance of EHRs, the MOH was moved to reform the current systems. Consequently, the Wareed project (new health information system) was defined. On the basis of this project, the HIS package was prepared by Cerner Corporation with the help of a consortium of companies including hybrid health solution, business machines, Injazat data systems, Mubadala owned, that will be implemented by I-capital Corporation in all public hospitals, health centers and clinics during 2009-2011. On the basis of the contract, after the finalization of the project, for up to 5 years it will be managed by the company (I-capital) and, after 5 years of operations, will be entrusted to the MOH. With the implementation of the project, EHRs are set up for each UAE citizen, and any existing files on the previous system will also enter the new system. By the beginning of the year 2012, the project had been implemented in half of the hospitals, health centers and clinics (21-23).

\subsection{Saudi Arabia}

The introduction of information technology to healthcare centers and hospitals of Saudi Arabia, dates back to the 1970s. At the beginning of the 1970s, King Faisal Specialized Hospital was the first hospital where an HIS was implemented. In 1988, through adopting a national plan to develop ICT in the health sector, ICT infrastructure in the health sector was supported. The ICT Department in the MOH was also responsible for HIT. Afterwards, in 2000, the Government of Saudi Arabia formed a health reform and improvement committee to evaluate the healthcare system. The committee revealed that one of the weak points in the current healthcare system is having no-proper software and application dealing with the field of Health Informatics. In 2002, this committee formed a special group on health IT strategic plan compilation, whose main objective was the creation of a national EHR. By compiling the program, master's degree in health informatics and Health Informatics Association were formed. Up to 2005, some of the country's hospitals have lacked mechanized information systems, and most hospitals have also used different information systems. Therefore, until 2005, hospitals and healthcare centers had not been connected to each other. In the years 2006 and 2008, e-health conferences were held that expressed HIS as a vital topic. Accordingly, in 2008, the government began the operational phase of the national e-health plan. Saudi Arabia ehealth project was divided into 100 sub-projects, the HIS program entitled HIS strategy was one of the most significant sub-projects. In the new HIS strategy, all hospitals of the state were defined in terms of their beds and 
HISs. Some rated full and comprehensive enterprise HIS, some with partial mechanization and some without computerized information systems. According to HIS criteria provided by the MOH, three HIS vendors were accepted at the national level. Also, it was supposed that during a ten-year e-health project, these three HISs will have been set up in the country by the end of the sixth year, to be able to communicate with each other, other health centers and also the data center of the Ministry of Health (24-27). Siemens, HIMSS, and I-clinic are some of the active companies in the field of HIS in this country. In cooperating with a local partner (Computer and Electronics Equipment Company), HIMSS (Health Information Management and Systems Society) Company has launched its HIS software in 30 hospitals over 24 months, since 2008. In 2010, making connection between these systems was taken into consideration as one of the important activities of this company. Now, in most hospitals (more than 200 hospitals and clinics), HIS is implemented having made some parts interconnected (28-31).

\subsection{Iran}

IT usage in the healthcare centers of Iran dates back to the early 1980s (IT uses in medical laboratories). The first HIS implementation was in Hashemi Nejad hospital in Tehran in the 1990s (3, 14). Moreover, during the 1990s, some HIS vendors were established in Iran. In this decade, no considerable actions were observed to be taken by the $\mathrm{MOH}$ about HIS at national level, except for several items including setting the Ministry of Health Informatics Council as responsible for HIT in the country, as well as introducing some features and criteria for HISs selection. In the 2000s, with the approval of an ICT development plan by the Board of Ministers, the Secretariat of TACFAB in the MOH was formed, to be responsible for HIT and HIS. Since the formation of the Secretariat, its officials carried out some activities. Finally, after approximately five years and despite offering two national projects and doing some work on the last national plan, plans failed for various reasons. Therefore, in 2007, the Center of TACFAB broke and the Centre of IT and statistics management was formed under the direct supervision of the Health Minister. The Centre of IT and Statistics Management studied the past activities, then, in its first major action, started the evaluation of the existing HISs, and introduced SEPAS project in order to create EHR. The first stage of HIS evaluation was done in 2010. This year's evaluations indicated that there were 22 HIS vendors in Iran, 16 of which are certified to comply with the SEPAS project. In this project, SEPAS will act as a middleware component so that it can connect existing HISs to each other. Schedule for the realization of the SEPAS project and the creation of EHR for every citizen lasted until the end of 2018. Now, from 856 active hospitals of the MOH, more than 80 percent of hospitals as well as other hospitals in all major cities of the country have HIS. Existing HISs covers functions such as administrative, financial, admissions, discharge, transfers, Para clinical data and very limited clinical functions $(14,32-35)$. A summary of the situation of hospital information systems of the studied countries is shown in Table 1.

Table 1. The situation of HISs of the countries of the Persian Gulf region

\begin{tabular}{|c|c|c|c|c|c|}
\hline \multirow[t]{2}{*}{ Criteria } & \multicolumn{5}{|l|}{ Countries } \\
\hline & Bahrain & Oman & U.A.E. & Saudi Arabia & Iran \\
\hline First HIS usage & Since 1980s & Since $1986^{*}$ & Since 1990 s & Since 1970s & Since 1990s \\
\hline $\begin{array}{l}\text { How to Use } \\
\text { HIS }\end{array}$ & A single HIS until 2000 & $\begin{array}{l}\text { In-house } \\
\text { developed HIS }\end{array}$ & $\begin{array}{l}\text { Different HIS } \\
\text { until } 2008\end{array}$ & $\begin{array}{l}\text { Different HIS until } \\
2005\end{array}$ & $\begin{array}{l}\text { Different HIS until } \\
2008\end{array}$ \\
\hline $\begin{array}{l}\text { The Evolution } \\
\text { and Integrity of } \\
\text { HISs }\end{array}$ & $\begin{array}{l}\text { From } 2000 \text { with } \\
\text { definition of MHIS } \\
\text { project }\end{array}$ & $\begin{array}{l}\text { From } 2004 \text { with } \\
\text { definition of } \\
\text { e-health project }\end{array}$ & $\begin{array}{l}\text { From } 2008 \text { with } \\
\text { definition of } \\
\text { Wareed project }\end{array}$ & $\begin{array}{l}\text { From } 2008 \text { with } \\
\text { definition of } \\
\text { e-health project }\end{array}$ & $\begin{array}{l}\text { From } 2008 \text { with } \\
\text { definition of } \\
\text { SEPAS project }\end{array}$ \\
\hline EHR creation & $\begin{array}{l}\text { End of } 2010 \text { with MHIS } \\
\text { project }\end{array}$ & $\begin{array}{l}\text { End of } 2010 \text { with } \\
\text { national } \\
\text { repository of EHR }\end{array}$ & $\begin{array}{l}\text { End of } 2011 \text { with } \\
\text { Wareed project }\end{array}$ & $\begin{array}{l}\text { From } 2014 \text { with e- } \\
\text { health project }\end{array}$ & $\begin{array}{l}\text { End of } 2018 \text { with } \\
\text { SEPAS project }\end{array}$ \\
\hline
\end{tabular}

UAE: United Arab Emirates; *Royal Hospital

\section{Discussion}

HISs are raised as one of the most important health information systems in each country (2). Therefore, since the 1960s, hospitals in developed countries including the USA have used HISs in order to improve the daily operations and quality of health care services (6). The survey of HISs usage in the studied countries indicated that these countries used the technology with a delay to an average of about two decades. The first was in King Faisal Specialized Hospital in Saudi Arabia in the 1970s and the latest date referred to Hashemi Nejad Hospital which is located in Tehran, the capital of Iran, in the 1990s $(24,14)$. Of course, such a finding is predictable since the promotion of technology producers in other countries is usually with a delay, especially in the first decades of the twentieth century, when information and communication technology were not advanced compared with today. A 
study conducted by Nabali (1991) demonstrated that in Arab countries of the Persian Gulf region, hospitals under the supervision of the Ministry of Health have used less computerized information systems in comparison with other hospitals in public and private sectors. She also suggests that one of its vital causes can be the lack of a clear relationship between the various parts of the economy in order to support and facilitate the use of new technologies, despite being national policies in these countries in order to expedite and facilitate the process of hospital mechanization (36). Concerning the use of HISs, the reviewed countries have employed different approaches. Bahrain, Saudi Arabia and the UAE are among the countries that have used external products, and in some cases, internal companies have also shared the production and implementation of HISs. By the year 2008, Saudi Arabia and the UAE had no plans to limit HISs, but in 2008, Saudi Arabia limited HIS to three and the UAE to one product. Since 1992, Bahrain has followed the approach of one product. Also, Oman placed on the agenda, the strategy of the creation of an HIS systems by the Ministry of Health in 1990. In Iran, in this respect, there has been much discussion, particularly between the years 2001-2006, but internal HISs are used for various reasons such as the important software market in the country. In addition, there are a total of 22 HISs vendors in Iran that are not supposed to be limited. Studies in China also indicated that more than 90 percent of hospitals in this country use HIS packages produced in the country, and there are very few hospitals that use external HISs. In China, there are about 500 software vendors in health information systems from which 300 firms work on HISs. Additionally, in 2007, on the basis of a review carried out by the Ministry of Health, 2,176 hospitals out of 3,765 have used ready HISs (HIS package) in comparison with the production of HIS by hospital or shared HISs (7). However, with respect to the use of HISs, the reviewed countries have employed different approaches. Perhaps we cannot say which approach suits best, but it must be noted that in adopting any approach, some factors must be met such as legal, financial, technical support, security, and technology transfer. Therefore, the use of internal HISs with regard to national and international standards and laws can be one of the appropriate approaches. In this respect, Haux, and Moghaddasi et al. pointed to topics such as HIS's strategy at the level of the enterprise, national and international levels, reviews of new methods in HIS architecture, education of health informatics and Biomedical informatics, and continued research on HISs $(3,37)$. The analysis of the findings indicates that the countries from the first use of HISs have not focused on issues of integrity and exchange of information between HISs. Despite the years 1990-2000, one of the most important topics discussed was HISs integrity and communication, also, the WHO stressed the nationwide compatibility among health information systems (38), therefore, it seems that the mentioned countries have continued the same way as the leading countries. Thus, Bahrain in 2002, Oman in 2004, UAE and Saudi Arabia in 2008, and Iran in 2010 started serious actions for the integrity of HISs. The countries have employed different techniques for communication and integration of HISs to create a repository of national EHR. These methods varied from using a middleware to defining a comprehensive project on health information systems or e-health. However, the integrity of HISs is inevitable in any country. The National Academy of Medicine, in its reports, has also pointed out the importance of computerized patient records and the integrity of information in the health care industry to provide better services. Studies have also shown that proper set up of electronic patient records could be saving hospital costs annually from 12.7 to 36 billion dollars (39). However, according to the analysis of the results of this study, for better use of health information technology in the health sector, especially HISs, it is necessary to consider issues such as using the experience of leading countries and not repeating their mistakes, considering the guidelines of international organizations, considering national and international needs, and finally developing a comprehensive plan for country health information systems with an emphasis on HISs, by taking into account national and international standards.

\section{Conclusions}

Despite several years of delay in the implementation and use of HISs in the hospitals of the reviewed countries in the Persian Gulf, the officials of the countries have realized the importance of information systems, in particular HISs, to support health care management. These countries in use of computerized information systems in healthcare centers, have adopted various approaches. Some of them have had specific plans and policies for HISs and some countries that have faced failures in some cases, have been planning for years. However, in order to prevent the wasting of resources such as human and financial ones, using successful experiences of other countries along with formulating a comprehensive plan for all aspects of HISs, considering national and international standards, is highly recommended.

Acknowledgments:

Thanks to Mrs. Somayeh Abedian, an expert in the Office of Statistics and Information Technology at the Ministry of Health, for her cooperation in providing the necessary information on the research. 


\section{Conflict of Interest:}

There is no conflict of interest to be declared.

\section{Authors' contributions:}

All authors contributed to this project and article equally. All authors read and approved the final manuscript.

\section{References:}

1) Johns ML. Information management for health professions. 2 ed. New York: Delmar Pub; 2002.

2) Peng F, Street B, Kurnia S. Understanding Hospital Information Systems Adoption in China.2010, Available from: Http://www.Pacis-Net.Org/File/2010/S05-02.Pdf.

3) Moghaddasi H, Asadi F, Hossaini A, Mohammadpour A. Hospital information system in Iran: findinges from a systematic review. Hakim Research Journal. 2013; 16(3): 228-35.

4) Staggers N, Thompson CB, Snyder-Halpern R. History and Trends in Clinical Information Systems in the United States. Journal Of Nursing Scholarship. 2001; 33(1): 75-81. doi: 10.1111/j.15475069.2001.00075.x.

5) Van de Velde R, Degoulet P. Clinical information systems: a component-based approach. New York: Springer; 2003. doi: 10.1007/b97438.

6) Borzekowski R. Measuring the cost impact of hospital information systems: 1987-1994. Journal of health economics. 2009; 28(5): 938-49. doi: 10.1016/j.jhealeco.2009.06.004.

7) China Hospital Information Management Association. The White Paper on China's Hospital Information Systems. $2008 . \quad$ Available from: http://www.chima.org.cn/pe/DataCenter/UploadFiles_8400/200812/20081219115545203.pdf

8) Fraser HSF, Biondich P, Moodley D, Choi S, Mamlin BW, Szolovits P. Implementing electronic medical record systems in developing countries. Informatics in primary care. 2005; 13(2): 83-96. doi: 10.14236/jhi.v13i2.585.

9) Mokhtaripoor M, Siadat S. Information Technology in the hospitals of Isfahan: suggesting a model. Health Information Management. 2008; 5(1): 251-9.

10) Eckman B. Information Integration for Healthcare Interoperability. 2010. Availble from: http://db.cis.upenn.edu/iiworkshop/postworkshop/positionPapers/Eckman.pdf.

11) Adler-Milstein J, Jha AK. Sharing Clinical Data Electronically A Critical Challenge for Fixing the Health Care System. JAMA. 2012; 307(16): 1695-6. doi: 10.1001/jama.2012.525.

12) Mustafa Hassan Q Ra, Leon D. E-health Readiness among Four Middle East Countries: Implications of SWOT Analysis. 2010. Available from: http://www.sahi.org.sa/2008/Saudi_ehealth_manuscript_with_authors\%20\%20-\%20Final.pdf

13) Igira FT, Titlestad $\overline{\mathrm{OH}}$, Lungo JH, Makungu A, Khamis MM, Sheikh Y, et al. Designing and implementing hospital management information systems in developing countries: case studies from Tanzania-Zanzibar. Health Informatics in Africa (HELINA). 2007.

14) Iran Ministry of Health. The history of Electronic Health Record in Iran. Tehran: ministry of health. 2009. Available from: http://it.behdasht.gov.ir/uploads/101_812_8.pdf.

15) Jalalian M. Writing an eye-catching and evocative abstract for a research article: A practical approach. Electronic Physician. 2012; 4(3): 520-4. doi: 10.14661/2012.520-524.

16) Bahrain Ministry of Health. Bahrain Health Strategy: Framework for Action. Manama: Ministry of health 2002. Available from: http://www.moh.gov.bh/pdf/bahrainhealthstrategy.pdf.

17) Bahrain Ministry of Health. Outsourcing Services for a Global Health Information System: Health IT. BDO Jawad Habib Consulting WLL Manama. 2007. Available from: http://www.moh.gov.bh/PDF/HealthIT/RFP\%20Presentation\%20to\%20Potential\%20Bidders.pdf

18) Bahrain Ministry of Health. Health information and communication technology strategy. Manama: ministry of health. 2003. Available from: http://www.moh.gov.bh/PDF/Publications/Policies/Health\%20Info\%20Com\%20Tech.pdf

19) Elhadi M, Day KH, Al-Hamadani A, Al-Toqi A, Al-Hashmi A, Al-Shamli N. Review of Health Information Systems in Oman. SQU Journal For Science. 2007; 12(2): 101-20. doi: 10.24200/squjs.vol12iss2pp101-120.

20) WHO. Health Systems Profile- Oman- Regional Health Systems Observatory- EMRO. Cairo: WHOeastern meditranean office. 2006.2 Available from: http://gis.emro.who.int/HealthSystemObservatory/PDF/Oman/Full\%20Profile.pdf 
21) United Arab Emirate Ministry of Health. Who we are (WAREED). 2012. Available from: http://www.wareed.ae/who_we_are.html

22) Ameinfo. New health information system in UAE to be connected via an online network by 2011. 2008. Available from: http://www.ameinfo.com/171847.html

23) United Arab Emirate Ministry of Health. MOH launches Wareed to create health database and link 82 hospitals and clinics across the UAE. 2009. Available from: http://www.belbadi.com/index.php?option=com_content\&view=article\&id=92:moh-launches-wareed-tocreate-health-database-and-link-82-hospitals-and-clinics-across-the-uae\&catid=3:latest-news\&Itemid=14.

24) Saudi Arabia Health Informatics. Health informatics: Saudi Arabia. 2011. Available from: http://www.sahi.org.sa/E-HealthWithinSA.php

25) Almalki M, Fitzgerald G, Clark M. Health care system in Saudi Arabia: an overview. East Mediterr Health J. 2011; 17(10): 784-93. PMID: 22256414.

26) Ministry of Health Saudi Arabia. Overview of e-Health. 2008. Available from: http://www.moh.gov.sa/en/Ministry/nehs/Pages/Overview-of-eHealth.aspx.

27) Altuwaijri M. Supporting the Saudi e-health initiative: the Master of Health Informatics programme at KSAU-HS. East Mediterr Health J. 2010; 16(1): 119-24. PMID: 20214169.

28) Itacksolutions. Hospital Information System in Saudi Arabia. 2011. Available from: http://itacksolutions.com/hospital-information-system-in-saudi-arabia.

29) East Health Management. 30 Connected e-Hospitals in 24 Months: A Saudi Case Study. 2010. Aailable from: http://www.himss.org/content/files/MiddleEast10_presentations/IS3_HealthInsightsNasserShehata.pdf.

30) Commission CaIT. Saudi Arabia- towards the Information Society. 2005. Available from: http://www.yesser.gov.sa/ar/mediacenter/DocLib1/ksa_to_information_society.pdf.

31) Siemens. Siemens in Saudi Arabia. 2007. Available from: http://www.siemens.com/about/pool/regions/saudi_arabia_2007_en.pdf.

32) Iran Ministry of Health. The framework for Hospital Information Systems evaluation. Tehran: Ministry of health 2010. Available from: http://it.behdasht.gov.ir/uploads/101_1475_HIS_Evaluation.pdf.

33) Iran Ministry of Health. The results of Hospital Information Systems's evaluation. Tehran: Ministry of health $2010 . \quad$ Available from: http://it.behdasht.gov.ir/index.aspx?siteid=101\&pageid=274\&newsview=63561.

34) Iran Ministry of Health. Health Information Technology policy in Iran. Tehran: Ministry of health; 2011. Available from: http://ihm.behdasht.gov.ir/Images/UserFiles/26/file/Health\%20MapIT\%20Final\%20Report $\% 20 v \_1 . p d f$

35) Iran Ministry of Health. SEPAS project in Iran. 2011. Available from: http://it.behdasht.gov.ir/index.aspx?siteid=101\&siteid=101\&pageid=20351.

36) Nabali HM. Hospital information systems in Arab Gulf countries: Characteristics of adopters. Journal of Information \& management. 1991; 20(5): 323-32. doi: 10.1016/0378-7206(91)90031-V.

37) Haux R. Health information systems? past, present, future. International Journal of Medical Informatics. 2006; 75(3-4): 268-81. doi: 10.1016/j.ijmedinf.2005.08.002.

38) WHO. Design and implementation of health information systems. 2000.

39) Health Information Management Systems Society. Electronic Health Records: A Global Perspective. New York: Healthcare Information and Management Systems Society (HIMSS). 2008. Available from: http://www.himss.org/content/files/200808_EHRGlobalPerspective_whitepaper.pdf 